\title{
Debilitated shock escape is produced by both short- and long-duration inescapable shock: Learned helplessness vs. learned inactivity
}

\author{
AIDAN ALTENOR, JOSEPH R. VOLPICELLI, and MARTIN E. P. SELIGMAN \\ University of Pennsylvania, Philadelphia, Pennsylvania 19104
}

\begin{abstract}
Inescapable shocks of short $(.5 \mathrm{sec})$ and long $(5 \mathrm{sec})$ duration interfered with subsequent shock escape in rats. In addition, there were no differences between groups that received the pretreatment shocks and testing in the same or different apparatuses. These results are consistent with the learned helplessness account but conflict with recent learned inactivity accounts for the interference effects produced by inescapable shocks.
\end{abstract}

Exposure to inescapable shock typically interferes with the subsequent acquisition of escape behavior, but exposure to equivalent amounts of escapable shock does not (e.g., Maier, Albin, \& Testa, 1973; Seligman \& Beagley, 1975). The learned helplessness hypothesis claims that animals exposed to inescapable shock learn that their behavior is independent of shock termination. This learning leads to the expectation of "nothing I do matters," and this expectation (1) decreases motivation to initiate escape behavior and (2) decreases ability to associate future responding and shock termination (Maier \& Seligman, 1976; Maier, Seligman, \& Solomon, 1969; Seligman, Maier, \& Solomon, 1971).

Several alternative hypotheses have been proposed to account for the helplessness effects observed in rats. Each is based on the premise that during inescapable shock the rat adventitiously learns responses that later interfere with appropriate escape behavior (Anisman, deCatanzaro, \& Remington, 1978; Bracewell \& Black, 1974; Glazer \& Weiss, 1976a, 1976b; Levis, 1976). One version of these competing response theories suggests that it is the motor response of inactivity that is adventitiously reinforced during inescapable shock. Rats typically engage in frantic active behavior during the initial 2-3 sec of shock (motor-activation phase); then, responding decreases dramatically. The learned inactivity theory (e.g., Anisman et al., 1978; Glazer \& Weiss, 1976a, 1976b) claims that if shock durations are longer than $3 \mathrm{sec}$, inactivity will coincide with shock termination and the animal will learn to become

This research was conducted under the auspices of NIMH Postdoctoral Fellowship 1F32MH07682-01 to A. Altenor, NIH Medical Scientist Training Grant GM 07170 to J. R. Volpicelli, NIMH Grant 19604 to M. E. P. Seligman, and NSF Grant BNS7622943A02 to the Center for Advanced Studies in the Behavioral Sciences. Requests for reprints may be sent to any of the authors, Department of Psychology, University of Pennsylvania, 3815 Walnut Street, Philadelphia, Pennsylvania 19104. passive adventitiously. If shocks are shorter than $3 \mathrm{sec}$, however, the active behavior of the motor-activation phase coincides with shock termination, and no interference effects should be observed. Indeed, Anisman et al. (1978) found that 2-sec durations of inescapable shock did not interfere with later escape in mice but that 6-sec duration shocks did, and Glazer and Weiss (1976a) reported no interference with inescapable shocks of 2 , 3 , and $4 \mathrm{sec}$ durations when rats were tested $72 \mathrm{~h}$ after pretreatment. Both learned helplessness and learned inactivity theories predict interference effects $24 \mathrm{~h}$ later if inescapable shocks of over $3 \mathrm{sec}$ duration are used; however, learned inactivity theory alone predicts no interference with shorter duration shocks.

The findings of Anisman et al. (1978) and Glazer and Weiss (1976a) surprised us, since in our own pilot work and in a number of other studies, interference effects were observed in rats with shocks of less than $3 \mathrm{sec}$ duration (e.g., Altenor, Kay, \& Richter, 1977; Kelsey, 1977). In these experiments, however, a yoked design was used that allowed variations in the duration of shock from trial to trial, with some trials consisting of long-duration shocks. Accordingly, this experiment examined the effects of short-duration shocks $(.5 \mathrm{sec})$ in subsequent escape behavior in the rat relative to long-duration shocks $(5 \mathrm{sec})$, equated for total amount of shock (after Overmier \& Seligman, 1967). We were also interested in the transfer of interference from one apparatus to another, reflecting a general expectation of response-reinforcer independence rather than inactivity associated with particular apparatus cues.

\section{METHOD}

\section{Subjects}

The subjects were 50 male Sprague-Dawley rats obtained from the Holtzman Company, Madison, Wisconsin. The animals were 90-110 days old at the start of the experiment and were individually housed for 10 days prior to the start. Animals were 
allowed free access to food and water under a 12-h light/dark cycle. All experimental manipulations were carried out during the light phase of the cycle.

\section{Apparatus}

The animals were exposed to inescapable shock in one of two units: two shuttleboxes or two barpress boxes. Each shuttlebox was $47.0 \mathrm{~cm}$ long, $20.4 \mathrm{~cm}$ wide, and $19.7 \mathrm{~cm}$ high. The walls were constructed of stainless steel and the ceiling was of clear acrylic plastic. The floor was a stainless steel grid with bars $.4 \mathrm{~cm}$ in diameter, $1.9 \mathrm{~cm}$ apart. The chamber was divided into two identical sections by a metal divider with a rounded archway $7.8 \mathrm{~cm}$ high and $5.8 \mathrm{~cm}$ wide cut out of the bottom of it. Each barpress box was $30.5 \mathrm{~cm}$ long, $20.4 \mathrm{~cm}$ wide, and $19.7 \mathrm{~cm}$ high. The floor was a stainless steel grid with bars $.64 \mathrm{~cm}$ in diameter, $1.9 \mathrm{~cm}$ apart. The long sides of each box were constructed of clear acrylic plastic; the end walls were of stainless steel. Centered on the right-hand wall was a lever $6.8 \mathrm{~cm}$ wide protruding $1.5 \mathrm{~cm}$ into the box and $6 \mathrm{~cm}$ above the grid floor. Each unit was housed in a sound-attenuating chamber with 76-dB background noise supplied to the experimental room. A .7-mA scrambled shock was delivered to the grid floor and metallic sides of each unit. The shock source consisted of a $600-\mathrm{V}$ ac transformer with a limiting resistor that supplied a constant-current shock through a Hoffman-Flesher (1962) scrambler to the shuttleboxes and a Lafayette scrambler (Model 82500) to the barpress boxes.

\section{Procedure}

The animals were nonsystematically assigned to one of five groups. A nonpreshocked group $(\mathrm{n}=10)$ served as controls. Of the remaining animals, one half received 605 -sec shocks either in the shuttleboxes or in the barpress boxes (with the levers removed) on Day 1. The other half received 600 .5 -sec shocks in one of the two units. For the 5-sec shock groups, shock was delivered on a variable-time 60 -sec schedule (range $=10-110 \mathrm{sec}$ ); for the .5 -sec groups, shock was delivered on a variable-time 6-sec schedule (range $=1-11 \mathrm{sec}$ ). On Day 2, all animals were tested on the acquisition of a leverpress response to escape from shock in the barpress boxes. The test consisted of 15 trials of up to $30 \mathrm{sec}$ of unsignaled .7-mA shock delivered on the variable-time 60 -sec schedule used with the 5 -sec shock groups. Shock was terminated when the rat depressed the lever three times (FR-3).

\section{RESULTS AND DISCUSSION}

All the preshocked groups did worse at escape than the nonshocked controls, but they did not differ from each other. Table 1 presents a summary of the findings. Preplanned comparisons among the preshocked groups revealed no reliable effects for either shock duration or place of pretreatment (all Fs $<1$ ) when analyzed for escape latency or number of failures to escape. However, the preshocked groups, taken together, were slower to escape than the nonpreshocked group $[F(1,45)=5.61$, $\mathrm{p}<.025]$, and they also had more failures to escape $[\mathrm{F}(1,45)=7.20, \mathrm{p}=.01]$.

As shown in Table 1, the animals pretrained in the shuttlebox did as poorly as the animals pretrained in the barpress box. This indicates that the interference effect is not specific to the location at which inescapable shocks occur. This supports the notion that helplessness effects reflect a generalized state and are not place specific. More important, shock duration in pretreatment had no differential interference effect. Contrary to the prediction of the learned inactivity hypothesis, the short-duration shocks interfered with later escape responding, as did long-duration shocks.

While both learned helplessness and learned inactivity theories readily account for the interference effects produced by inescapable shocks of $5 \mathrm{sec}$ duration, only the learned helplessness theory predicts the effects observed with the .5 -sec duration shocks. Can the learned helplessness theory account for the reported failure of 2-sec duration shocks to produce interference in the studies by Anisman et al. (1978) and Glazer and Weiss (1976a)? In only one experiment (Anisman et al., 1978, Experiment 10) are 6-sec duration shocks compared with 2-sec duration shocks when each group received the same total amount and density of shock. If these two groups are compared, no reliable difference is observed. While only the 6-sec group reliably differs from the no-shock group, the differences between the 2 -sec group and the no-shock group are in the direction predicted by the learned helplessness theory. Glazer and Weiss (1976a, Experiment 2) report no differences between groups that received 2-, 3-, and 4-sec duration

Table 1

Mean Shock-Escape Latencies $(L)$ and Failures (F) to Escape in 15 Trials

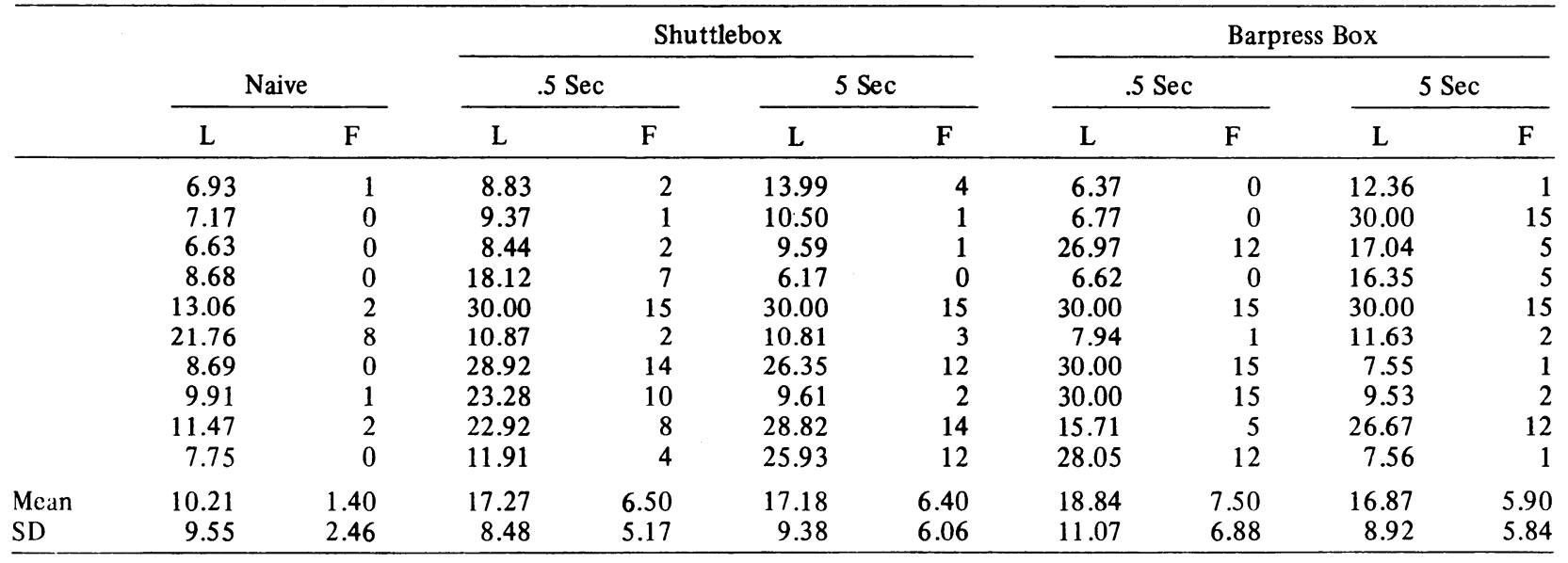


shocks, but they report that these groups were faster to escape from shock than animals that received 5. and 6-sec duration shocks when tested $72 \mathrm{~h}$ after inescapable shock. However, as Maier and Jackson (1979) report, exposure to 1802 -sec inescapable shocks produces as much interference as 725 -sec shocks when animals are tested $24 \mathrm{~h}$ later. Since Weiss' data are presented for performance $24 \mathrm{~h}$ after inescapable shock, we cannot compare their findings with ours. With respect to the Anisman et al. (1978) findings, we cannot explain why the interference effects obtained for the 2-sec group were not statistically reliable in their experiment, but our results suggest that their learned inactivity interpretation does not generalize beyond the parametric manipulations used in their own experiments. While the findings reported here differentiate between the learned helplessness and learned inactivity accounts, they do not rule out the possibility that the deficits that follow inescapable shocks are due to some neurochemical imbalance (e.g., Anisman, 1975).

\section{REFERENCES}

Altenor, A., Kay, E., \& Richter, M. The generality of learned helplessness in the rat. Learning and Motivation, 1977, 8, 54-61.

Anisman, H. Time-dependent variations in aversively motivated behaviors: Nonassociative effects of cholinergic and catecholaminergic activity. Psychological Review, 1975, 82, 359-385.

Anisman, H., deCatanzaro, D., \& Remington, G. Escape performance following exposure to inescapable shock: Deficits in motor response maintenance. Journal of Experimental Psychology: Animal Behavior Processes, 1978, 4, 197-218.

Bracewell, R. F., \& Black, A. H. The effects of restraint and noncontingent preshock in subsequent escape learning in the rat. Learning and Motivation, 1974, 5, 53-69.

Glazer, H. I., \& WeISS, J. M. Long-term and transitory inter- ference effects. Journal of Experimental Psychology: Animal Behavior Processes, 1976, 2, 191-201. (a)

Glazer, H. I., \& Weiss, J. M. Long-term interference effect: An alternative to "learned helplessness." Journal of Experimental Psychology: Animal Behavior Processes, 1976, 2, 202 213. (b)

Hoffman, H. S., \& Fleshler, M. A relay sequencing device for scrambling grid shock. Journal of the Experimental Analysis of Behavior, 1962, 5, 329-330.

KELSEY, J. E. Escape acquisition following inescapable shock in the rat. Animal Learning \& Behavior, 1977, 5, 83-92.

LEvis, D. J. Learned helplessness: A reply and an alternative S-R interpretation. Journal of Experimental Psychology: General, 1976, 105, 47-65.

Maier, S. F., Albin, R. W., \& Testa, T. J. Failure to learn to escape in rats previously exposed to inescapable shock depends on nature of escape response. Journal of Comparative and Physiological Psychology, 1973, 85, 581-592.

MAIER, S. F., \& J ACKSON, R. L. Learned helplessness: All of us were right (and wrong): Inescapable shock has multiple effects. In G. Bower (Ed.), The psychology of learning and motivation (Vol. 3). New York: Appleton-Century-Crofts, 1979.

Maier, S. F., \& Seligman, M. E. P. Learned helplessness: Theory and evidence. Journal of Experimental Psychology: General, 1976, 105, 3-46.

Maier, S. F., Seligman, M. E. P., \& Solomon, R. L. Pavlovian fear conditioning and learned helplessness. In B. A. Campbell \& R. M. Church (Eds.), Punishment. New York: AppletonCentury-Crofts, 1969.

Overmier, J. B., \& Seligman, M. E. P. Effects of inescapable shock upon subsequent escape and avoidance learning. Journal of Comparative and Physiological Psychology, 1967, 63, 28-33.

Seligman, M. E. P., \& Beagley, G. Learned helplessness in the rat. Journal of Comparative and Physiological Psychology, 1975, 88, 534-541.

Seligman, M. E. P., Maier, S. F., \& Solomon, R. L. Unpredictable and uncontrollable aversive events. In F. R. Brush (Ed.), Aversive conditioning and learning. New York: Academic Press, 1971.

(Received for publication August 1, 1979.) 